decomposed granite: solid granite is reached at a depth of $20 \mathrm{ft}$. These features, together with a light intermittent rainfall, help to account for the small yield of the reservoir, ranging as it does from a few hundred million to a little more than $20,000,000,000$ gallons per annum-not more than about $7 \frac{1}{2}$ per cent. of the rainfall. The consumption of water in the districts supplied has increased from an average of 600,000 gallons per day in 1903 to about $2,000,000$ gallons per day at the present time.

The success of the measures in course of adoption for the treatment of this grave difficulty of watersupply in Australia will be followed with interest, not merely by engineers and geologists, but by all who have at heart the development of the Empire, and its widespread capabilities for usefulness to mankind.

Brysson Cunningham.

\section{THE REPORT OF THE BOARD OF EDUCATION, I9I5-I6.}

$\mathrm{T}$

$\mathrm{E}$ report of the Board of Education for the year I915-I6 is a document to which, in the present state of public expectation, more than usual interest will be attached. It is naturally concerned in large measure with the work and problems of elementary education, upon which by far the larger proportion of the public funds are, by the very circumstances of the case, expended. But it is now fairly generally admitted that we cannot have a sound solution of the problems of education, or raise an educational edifice worthy of the name, or secure the right type of educated electorate, or place education upon its highest plane, unless we make much more adequate provision for the training of the great mass of the people.

A grave responsibility now rests upon the nation, in view of the devastating effects of the war, to provide with the utmost fullness possible for all its children the means of physical, mental, and moral health, and especially to secure ample educational opportunities for the worthy, no matter of what class. The claims of the war during the year under review upon the schools, upon the teaching staffs, even upon the pupils themselves in response to industrial and agricultural demands, have increased in intensity and with unfortunate results, since many school buildings have been closed either for the billeting of troops or for use as hospitals; the male teaching staffs have been seriously depleted; the classes have necessarily been enlarged, to the grave disadvantage of the pupils; and in many other ways the work of education has been impeded. There has been a serious decrease compared with I9I5 of nearly 26,000 pupils of twelve vears of age and upwards in the public elementary schools, due to the large number who have passed into employment.

The question of the supply of male teachers has become grave, even apart from the exigencies of the war, due in large measure to the inadequate salaries paid and to the poor prospects offered. In the year I9I6, on August $r$, the number of boy entrants to the teaching profession in England and Wales was 1063, of girls 5228 , or a total of $629 \mathrm{I}$; but the real annual demand for entrants, even under normal conditions, is 9000 , including men and women. Unless this grave deficiency can be met by satisfactory measures there can be neither any increase in the length of the school life nor reduction in the size of classes, and it will, moreover, gravely imperil the level of efficiency in the schools reached before the war. The number of men students in the training colleges has fallen from 4242 to about $\mathrm{I}_{5} \mathrm{Oo}$, and nearly 4000 men have joined the Army direct from them. It is now proposed, in order to increase the supply of candidates, to modify the NO. 2489, vOL. 99] requirements of the bursar system in the direction of the pupil-teacher methods of former days.

The work of the secondary schools, like that of the eiementary schools, has suffered much by reason of the war. The number of schools now recognised as efficient by the Board is 1178 , educating some 23I, ooo pupils, a vast advance upon days prior to 1902. Of this number about 9000 were displaced in 1916 by military or hospital occupation of school premises, and other provision far less adequate was made for them. The male staff of the secondary schools has also suffered much. Upwards of 2600 men have joined the Services since the beginning of the war up to October 3I, I9I6. Praiseworthy efforts have been made by the local education authorities and by the teachers of all graues to meet the untoward circumstances of the time, but, as may be expected with but partial success.

The attendance of students attached to technical schools, schools of art, and other schools and classes for further education has fallen considerably. Many of the schools have been engaged in munition work and in the training of munition workers. There was a serious diminution in 1916 in the evening and part-time schools, the number having fallen from 5413 to 3909 , as compared with 1915. Much praise is given in the report to the initiative, adaptability, and public spirit of the universities and technical colleges in meeting so successfully the demands set up by the war.

The universities and colleges have continued to make contributions of the highest value to the national cause in the prosecution of abstruse and laborious researches into technical matters bearing upon the war, and especially in the enlightenment and information of public opinion. All this has been done without in the least ceasing to provide for the needs of those able to pursue the ordinary courses of study. The Government has been able materially to aid in this development by financial assistance of a special nature. It is noted in the report with much satisfaction that greatly increased interest has been displayed by almost all sections of the Press and of the public in the possibilities and problems of the universities, than which there can scarcely be a more hopeful sign. "It is being realised," to quote the words of the report. " more clearly day by day how much the welfare and progress of the nation depend upon a highly equipped, accessible, and well-organised system of university education. .. The war has brought the professor and the manufacturer together, with results which neither is likely to forget." It has apparently taken a devastating war to bring about this consummation. Many important benefactions made to universities and colleges during ror 6 in aid of their respective spheres of work are noted in the report.

\section{THE CARNEGIE INSTITUTION AND SCIENTIFIC RESEARCH.}

F ROM the Igr6 Year Book of the Carnegie Institution of Washington we learn that the following grants have been authorised by the Board of Trustees for the current year :-
Administration

Publication

Division of Publications

Departments of Research

Minor Grants ...

Index Medicus

Insurance Fund

Reserve Fund ...
..

$\cdots$

$\cdots$

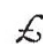

10,000

12,000

2, 100

I 26,670

$\mathrm{r} 9,360$

2,400

5,000

50,000 
Among the salient events in the work of the institution during the year under review the following facts referred to in the president's report may be mentioned. The roo-in. reflecting telescope at the Solar Observatory of the institution is nearly completed, and the observatory now possesses an unrivalled equipment for nearly all branches of stellar work, except that of positional astronomy, to which the institution is contributing substantial aid through its Department of Meridian Astrometry.

During the year the non-magnetic ship, Carnegie, has added an unexpectedly large mileage to her record. Leaving Lyttelton, New Zealand, on December 6, $19{ }^{1} 5$, she sailed round the world between parallels of $50^{\circ}$ and $60^{\circ}$ south latitude, a voyage of only 118 days, during which complete observations of the magnetic elements were made on every day except one. Sailing again from Lyttelton on May 17 , 1916, she arrived at San Francisco on September 2 I following.

The various editions of Ptolemy's "Almagest" have been collated and a new edition was issued by the institution during the ycar.

"This edition is a result of the joint researches of the late Dr. C. H. F. Peters and Mr. E. B. Knobel. In addition to the profound historical importance of this early work, a great and permanent merit of this latest edition lies in the data it affords for fixation of the relative precision of the ancient determinations of stellar positions. Our admiration for the Alexandrian school of astronomers need rot be diminished, however, by the fact that the precision now attained in such determinations is incomparably superior to that attainable by the pioneers in this science twenty centuries ago."

"During the past four years Dr. Frederic E. Clements, professor of botany in the University of Minnesota, has been attached to the department of botanical research as a research associate, and has extended the field studies and elaborated the inductions on which he had been at work previously for many years. The results of his investigations are embodied in a remarkable book entitled 'Plant Succession: An Analysis of the Development of Vegetation.' This work extends the concepts of Darwin and views the successive plant-complexes which invade any region as so many organic units, each enacting its rôle no less definitely than is enacted the rôle of an individual plant or other organism. This work of Prof. Clements brings the relatively new science of ecology and palæo-ecology prominently forward. It is instructive by reason of the analogies it suggests, especially to the student of contemporary events, between the struggle for existence of the lower species and the struggle for existence of the highest species in the biological world."

The public estimation of the value of research in science as a means of assisting the development of human institutions is referred to in the following paragraphs from the report:-

"Numerous references have been made in preceding reports to the growing realisation of the world at large that the methods of science are the most effective methods thus far developed for the advancement of learning and for the mitigation of the consequences of the inexorable 'laws of Nature' which condition existence on our planet. Reference has been made likewise to the contemporary rise and progress of other research establishments and to the introduction of investigation as an economic adjunct to industrial enterprises. These manifestations of popular approval and confidence continue to be among the most noteworthy signs of the times. Indeed, it is plain that we are now witnessing a remarkably rapid evolution of public understanding of the meaning and the value NO. 2489 , vOL. 99] of research. This has been greatly intensified and accelerated by the European war, the sinister aspects of which appear to be relieved in some degree by the prospects of an awakened realisation of the availability of better methods than those of warfare for settling international disputes, of better methods than those now commonly applied in the government of States, and of better methods in education, in sanitation, in industry, and in biological economy generally. The European war has emphasised to a degree not hitherto attained in the world's history the perils of ignorance, of government by assumed divine right, and of that sort of diplomacy which shades off by insensible degrees into duplicity; and it has emphasised equally clearly the necessity for rational investigation of, and progressive reforms in, all national affairs.

"How the details of this evolution, in which the in. stitution must participate, will work themselves out is impossible to predict except in general terms. It may be safely inferred, however, from the history of similar developments, that this one will proceed much more slowly and with much more difficulty than many enthusiastic optimists anticipate. Evolution is, in general, a secular process, and goes on with a leisurely disregard of individuals. It may be safely inferred also that many of the numerous fallacies which have beset the institution during the brief interval of its existence will recur again and again in the rise of similar organisations, while fallacies of a more troublesome type are likely to beset the introduction of the methods and the results of research in governmental affairs. It is in the latter affairs that the most stubborn opposition to progress is usually met, since there exist, as a rule, in such affairs no adequately developed relations of reciprocity between those best qualified to suggest and to formulate improvements and those who control the machinery for their applications. Such improvements can be secured only by overcoming a stolid adherence to precedent as well as the reluctance of rational conservatism.

"Thus it happens in governmental affairs that the most incongruous ideas often co-exist, as is well shown by the contemporary adoption of the most advanced principles of sanitation in certain European countries which are still dominated by medieval theories of the functions of a State. To cite another illustration readily understood and verifiable, it is an anomalous fact that the United States Government exacts no professional requirements for the direction of its highly technical affairs except in a single branch of its service, namely, the legal. And in line with this glaring national deficiency it is notorious that the fiat of an executive can make an astronomer, a geodesist, or a biologist out of a man whose works are unknown in the annals of the science of which he becomes the ex-officio representative.

"We hear much also in these days of the "mobilisation of genius' in the interests of national preparedness for commercial and industrial competition, if not for the more serious exigencies of national defence; but it is to be feared that this mobilisation means fruitless attempts to utilise aberrant types of mind, or perhaps the employment of men of talent under the direction of those whose competency for leadership is admitted, if at all, only in quite other fields of activity than those here considered. In the meantime, it is plain enough, in the lioht of current events, that any nation the governors of which mistake necromancy for science, confound inverrtion with investigation, or fail to utilise effectively available and advancing knowledge, is in danger of humiliation in peaceful international competition, if not in danger of extinction in

The principles which have guided the research work of the institution and the difficulties with which the 
trustees have had to contend are set out towards the end of the president's report in the following words :-

"All experience teaches that effective research depends on painstaking labour, arduously, patiently, and persistently applied; while all science teaches that research is elfective only in those regions wherein something like demonstration can $b=$ attained. investigations cannot be well done they are of little worth; if nothing can be proved they are of still less worth, or at best only of negative value. But obvious as these truisms are when stated by themselves, they have been contradicted daily in the plexus of events which make up what our successors will call the history, recorded and unrecorded, of the institution. 'Thus it has been suggested not infrequently that promising researches be suspended in order that equally or less promising researches might be taken up; and it has happened that proposals to abolish departments of research have been seriously advanced before these departments have had time to prove their rights to existence. It is not infrequently suggested, Iikewise, by otherwise irreproachable correspondents, that the experts of the laboratories and observatories of the institution be set at work under the direction of amateurs, or, in some cases, of those even who have not reached that earliest stage of capacity in science.

"It goes without saying that all such untoward influences should have little effect on the rise and progress of a research establishment; but he would be an incompetent administrator who failed to recognise the existence and the dangers of these influences. Most men are still opportunists; many contemn principles and theories of procedure; while the characteristic defect of deliberative bodies, strikingly illustrated by legislative assemblies, is lack of deliberation. Moreover, what any organisation, altruistic or otherwise, may accomplish at any epoch, or during any period, will depend very largely on the status of contemporary public opinion. No organisation may be rationally expected to rise much above the level of the ideals of those who support and direct it. The law of averages and the "law of conservation of ignorance' applv in the business of research no less rigorously than in other affairs of human endeavour. The only difference is that in research, from the nature of the case, we are held to stricter accountability; it is incumbent on us to be alive to the ideals and the theories which lead to regress as well as alive to the ideals and the theories which lead to progress

"Although popular opinion continues to look upon the institution as an establishment of unlimited means, and hence of unlimited capacities, it is an easily ascertained fact that such advances as have been attained are due chiefly to concentration of effort in a few fields of investigation, the number of these being necessarily limited by the finiteness of income. Of the agencies which have contributed most to these advances the departments of research must be given first rank when quality and quantity of results accomplished are taken in account. These departments have supplied also a much-needed verification of the axiom hitherto admitted in all domains of activity except those of research, namely, that if any good work is required the best way to get it done is to commit it to competent men not otherwise preoccupied. They have verified, likewise, the equally obvious truth that large and difficult undertakings demand foresight and oversight, prolonged effort, and a corresponding continuity of support. The idea that discoveries and advances are of meteoric origin and that they are due chiefly to abnormal minds has been rudely shattered by the remorseless experience of the institution.

"Along with these considerations special mention should be made of another of vital importance to the departments of research. This is their complete autonomy within the limits of their annual appropriations. Allusion is made to this matter here partly for the purpose of correcting public misapprehension concerning the relations of these departments to the institution as a whole, and partly for the purpose of stating formally the theory of administration followed by the institution during the past twelve years. Such a degree of freedom accorded to the departments of research is not only necessary by reason of the extent and the complexity of the affairs of the institution, but it should be regarded as a fundamental principle of sound administration. No one can follow the details of all these varied affairs. A division of labours is indispensable, and to the greatest extent practicable the director of a department of research should be encouraged to be the autocrat of his departmental destiny. But in so far as departments are granted liberty of action it is an equally fundamental principle of administration that they should assume corresponding responsibilities. Autonomous freedom and reciprocal accountability are then, in brief, the essentials of the theory under which the departments of research have evolved."

\section{UNIVERSITY AND EDUCATIONAL INTELLIGENCE.}

Birmingham.-Prof. Peter Thompson has been appointed Ingleby lecturer for the year 1918 .

The council has approved of a recommendation of the Senate that no degree congregation be held this year, and has requested the Vice-Chancellor to sign a special warrant conferring degrees in absentia.

The examiriation pass list just issued contains the name of Prof. J. H. Barnes, principal of the Agricultural College, Lyallpur, and agricultural chemist to the Punjab Department of Agriculture, who has been awarded the degree of D.Sc. for a thesis on "The Insects Attacking Stored Wheat in the Punjab and the Methods of Combating Them, including a Chapter on the Chemistry of Respiration." By a sad coincidence the death of Prof. Barnes, from enteric, has just been announced.

A donation of roool. to the funds of the University has been received from $\mathrm{Mr}$. F. W. V. Mitchell.

ONE chapter of the new Regulations for Secondary Schools [Cd. 854I] deals with the provision for advanced courses of instruction for pupils between the ages of sixteen and eighteen years of age, and with the financial aid which the Board is prepared to give towards the establishment of such courses. The regulations state that such courses are to be organised in three groups-science and mathematics, classics, and modern studies-and that schools recognised by the Board as fitted by staff, numbers, equipment, and so on, to undertake such work are eligible for grants up to $400 l$. for each course to defray the additional expenditure incurred. The introduction to the regulations indicates that the Board of Education contemplates that in large schools alone will it be possible to arrange advanced courses in each of the three groups, that in the majority of aided schools an advanced course in one subject only will be possible, while in some smaller schools it may not be possible to provide any such advanced teaching. Education authorities are recommended to arrange that each of the three groups shall be provided for in some school in their respective areas, and co-operation between the education authorities of adjoining areas is to be encouraged. Though difficulties in administration are bound to arise in connection with the inaugura-

NO. 2489 , VOL. 99] 